J. Lake Sci. (湖泊科学), 2019, 31(6): 1651-1661

DOI 10. 18307/2019. 0626

(c) 2019 by Journal of Lake Sciences

\title{
不同水位和竞争模式对典型湿地植物生态化学计量特征的影响”
}

\author{
李 旭 ${ }^{1}$, 于 洁 ${ }^{2}$, 李 峰 ${ }^{1}$, 胡 聪 $^{1}$, 曾 静 $^{1}$, 侯志勇 ${ }^{1}$, 谢永宏 ${ }^{1 * *}$, 陈心胜 ${ }^{1}$ \\ ( 1 : 中国科学院亚热带农业生态研究所, 亚热带农业生态过程重点实验室, 洞庭湖湿地生态系统观测研究站, 长沙 \\ 410125) \\ (2:包头市昆都仑区农牧局,包头 014010$)$
}

\begin{abstract}
摘 要: 以洞庭湖典型湿地植物辣苶为目标植物, 短尖苔草为邻近植物, 通过控制实验研究不同水位 $(30 、 0$ 和 $-30 \mathrm{~cm})$ 和 竞争 (无竞争、全部竞争、地上竞争和地下竞争) 模式下目标植物生长及生态化学计量特征的变化. 结果表明: 水位处理显 著影响不同竞争模式下的生物量积累, 辣苶生物量随水位增加显著降低; $-30 \mathrm{~cm}$ 水位无竞争模式下生物量最大, 为 $10.84 \pm 1.52 \mathrm{~g}$. 在 $30 \mathrm{~cm}$ 和 $0 \mathrm{~cm}$ 水位梯度下, 不同竞争模式下的生物量间无显著差异. 但 $-30 \mathrm{~cm}$ 水位下, 地下竞争模式下 的辣苶生物量积累较全竞争模式和地上竞争模式下显著增多, 说明非胁迫条件下, 辣苶和苔草的竞争以地上竞争为主. 水位处理对辣苶叶片、茎和根的氮、磷含量影响显著, $30 \mathrm{~cm}$ 水位下, 叶片氮、磷含量显著高于其他水位下的含量. 在 -30 $\mathrm{cm}$ 水位下, 叶片 $\mathrm{C}: \mathrm{N}$ 和 $\mathrm{C}: \mathrm{P}$ 显著高于其他水位下的比值, 分别为 $48.08 \pm 3.85 、 590.3 \pm 43.4$. 相比于对照处理 (无竞争), 竞 争作用下的辣苶总氮含量降低, 而 $\mathrm{C}: \mathrm{N}$ 值增加, $\mathrm{N}: \mathrm{P}$ 值降低, 这可能是因为竞争作用导致辣苶对氮的吸收减少所致.
\end{abstract}

关键词: 地上竞争;生态化学计量;生长速率假说;环境胁迫;辣苶;短尖苔草

\section{Effects of water level and competition pattern on ecological stoichiometry characteristics of a typical wetland plant Polygonum hydropiper in Lake Dongting}

\author{
LI Xu ${ }^{1}$, YU Jie ${ }^{2}$, LI Feng ${ }^{1}$, HU Cong ${ }^{1}$, ZENG Jing $^{1}$, HOU Zhiyong ${ }^{1}$, XIE Yonghong ${ }^{1 * *}$ \& CHEN Xinsheng ${ }^{1}$ \\ (1: Institute of Subtropical Agriculture, Key Laboratory of Agro-ecological Processes in Subtropical Region, Lake Dongting \\ Station for Wetland Ecosystem Observation and Research, Chinese Academy of Sciences, Changsha 410125, P.R.China) \\ (2: Agriculture and Animal Husbandry Bureau of Kundulun District, Baotou 014010, P.R.China)
}

\begin{abstract}
Taking Polygonum hydropiper as the target plant and Carex brevicuspis as the adjacent plant, the changes of growth and ecological stoichiometry characteristics of $P$. hydropiper under different water levels $(30 \mathrm{~cm}, 0 \mathrm{~cm}$ and $-30 \mathrm{~cm})$ and competition patterns (no competition, full competition, above-ground competition and below-ground competition) were studied through outdoor control experiments. The results showed that: the biomass accumulation of $P$. hydropiper was significantly affected by water level under different competition patterns, and which decreased significantly with the increase of water level. The maximum biomass was $10.84 \pm 1.52 \mathrm{~g}$ in the no competition pattern with the $-30 \mathrm{~cm}$ water level. Under $30 \mathrm{~cm}$ and $0 \mathrm{~cm}$ water levels, the biomass accumulation of $P$. hydropiper had insignificant difference under different competition patterns. However, at $-30 \mathrm{~cm}$ water level, the biomass accumulation of $P$. hydropiper under the below-ground competition pattern was significantly higher than that under the full competition pattern and the above-ground competition pattern, which indicated that the competition between $P$. hydropiper and $C$. brevicuspis was dominated by the above-ground competition under the non-stress condition. The nitrogen and phosphorus contents in leaves, stems and roots of $P$. hydropiper were significantly affected by water level. The nitrogen and phosphorus contents of leaves were significantly higher at $30 \mathrm{~cm}$ water level than those at other water levels. At $-30 \mathrm{~cm}$ water level, the ratio of $\mathrm{C}: \mathrm{N}$ and $\mathrm{C}: \mathrm{P}$ was significantly higher than those at other water levels, which was $48.08 \pm 3.85$ and $590.3 \pm 43.4$, respectively. Compared with the control treatment, competition decreased the total nitrogen content of $P$. hydropiper, while the $\mathrm{C}: \mathrm{N}$ ratio increased and the $\mathrm{N}: \mathrm{P}$ ratio
\end{abstract}

* 国家自然科学基金项目 $(31570431,41601106) 、$ 中国科学院重点部署项目 (KFZD-SW-318)、中国科学院青年创新 促进会项目 (2014337) 和湖南省自然科学基金项目 (2018JJ3580) 联合资助. 2019-07-15 收稿; 2019-09-11 收修 改稿. 李旭( 1985 ), 男, 工程师; E-mail: libr05008@ 139.com.

** 通信作者;E-mail: xyh@ isa.ac.cn. 
decreased, which may be due to that the competition reduced the nitrogen absorption of $P$. hydropiper.

Keywords: Above-ground competition; ecological stoichiometry; growth rate hypothesis; environmental stress; Polygonum hydropiper; Carex brevicuspis

生态化学计量学是结合生态学、化学和物理学的基本原理,利用生态过程中多重化学元素 (主要是碳 $(\mathrm{C}) 、$ 氮 $(\mathrm{N}) 、$ 磷 $(\mathrm{P}))$ 的平衡关系, 研究这些元素在生态系统过程中耦合关系的一种研究方法 ${ }^{[1,2]}$, 主要揭示 生物体内元素组成的差异性对生态系统功能的影响和响应. 当前, 该研究方法广泛应用于营养动态、微生物 营养、物种共生、生物养分循环、种群动态和生态系统养分供应与需求平衡等领域 ${ }^{[3,4]}$.

水文情势是湿地生态系统中最重要最典型的生态过程, 水位变化能影响植物的生长繁殖、群落分布、植 被演替等多个生态系统过程 ${ }^{[5-10]}$. 耐淹性植物可以通过改变代谢途径或者适应性机制以适应淹水环境 ${ }^{[11]}$, 例如, 调整其生物量分配模式 ${ }^{[12]}$ 、形成不定根 ${ }^{[13]}$ 、叶片变薄或形成气生叶 ${ }^{[14]}$ 等. 这些调节对植物的养分吸 收具有显著影响, 进而影响植物生态化学计量学特征. 例如: 在持续淹水条件下, 植物由有氧呼吸转为无氧 呼吸, 碳水化合物利用率以及体内养分储备减少 ${ }^{[15-17]}$, 植物根系大量矿质元素淋溶丢失, 植物体内 $\mathrm{C}$ 含量降 低, 同时抑制植物根系对 $\mathrm{N}$ 的吸收和有效 $\mathrm{N}$ 的矿化速率, 从而降低植物 $\mathrm{N}$ 含量 ${ }^{[18-20]}$.

竞争是塑造植物形态、调节植物生活史以及群落结构和动态特征的重要因素之一, 因而受到了越来越 多的群落生态学家的关注 ${ }^{[21-24]}$. 植物之间的竞争包含对地上 (光、热) 和地下资源 (水分、矿质营养) 的争 夺 ${ }^{[25]}$. 地下竞争和地上竞争作用大小及相对重要性, 对了解植物竞争过程, 揭示竞争机理具有重要的理论 意义 ${ }^{[26]}$. 地上竞争和地下竞争可能交互地影响植物的生长, 它们之间存在着一种权衡关系 ${ }^{[27]}$. 如: 光竞争假 说预测, 当土壤资源从匮乏到丰富时, 竞争可能会发生地下竞争到地上竞争的转移 ${ }^{[28-29]}$. 地上竞争和地下竞 争过程中植物对土壤营养、光等资源吸收的变化也将影响到植物生态化学计量学特征 ${ }^{[30]}$, 而这种变化的程 度取决于所涉及的植物种类、环境胁迫程度及种类等 ${ }^{[31]}$.

近年来, 受全球变化及高强度人类活动的影响, 尤其是三峡工程运行后, 洞庭湖水位不断降低, 洲滩湿 地提前出露, 导致洞庭湖湿地植被呈现明显的正演替趋势, 群落分布带不断下移 ${ }^{[32]}$. 此过程中, 水位的变化 和植物间的竞争关系都将对植物的生长和分布产生很大的影响. 目前, 相关研究主要集中在水位和竞争对 植物的生长和分布的影响 ${ }^{[33-34]}$, 而对于不同水位条件下植物间不同竞争模式对植物生态化学计量特征的研 究则较少 ${ }^{[35-39]}$. 因此, 本文以洞庭湖典型湿地植物辣苶 (Polygonum hydropiper) 为目标植物, 短尖苔草 (Carex brevicuspis) 为邻近植物, 研究不同水位条件和竞争模式下种间关系及生态化学计量特征的变化, 以期为洞庭 湖湿地的生态修复和保护提供一定的理论依据.

\section{1 材料和方法}

\section{1 实验材料和研究区概况}

以洞庭湖湿地典型植物辣苶为目标植物, 短尖苔草为邻近植物. 短尖苔草是多年生莎草科植物, 秆高 $20 \sim 55 \mathrm{~cm}$, 分布于洞庭湖湿地海拔 $26 \sim 28 \mathrm{~m}$ 范围内, 主要通过地下芽库进行克隆繁殖, 根系集中在 $0 \sim 20 \mathrm{~cm}$ 土层内. 辣菶在洞庭湖湿地属于多年生植物, 分布于海拔 $27 \sim 30 \mathrm{~m}$ 范围内, 主要通过地下根茎越冬繁殖. 在 洞庭湖区这 2 种植物通常混生在一起, 竞争作用较为明显.

控制实验在位于湖南省岳阳市君山区的中国科学院洞庭湖湿地生态系统观测研究站控制试验场内进 行. 该区属亚热带季风气候, 年平均气温 $16.4 \sim 17.0^{\circ} \mathrm{C}$, 无霜期 $260 \sim 280 \mathrm{~d}$, 年平均降水量 $1250 \sim 1450 \mathrm{~mm}$, 年 平均湿度 $80 \%$.

\section{2 试验设计}

2018 年 4 月, 在君山区小西湖湿地内 (图 1) 采集短尖苔草和辣苶的地下根茎和土壤(有机质含量 28.66 $\mathrm{g} / \mathrm{kg}$, 全氮含量 $1.3 \mathrm{~g} / \mathrm{kg}$, 全磷含量 $0.75 \mathrm{~g} / \mathrm{kg}$, 全钾含量 $32.1 \mathrm{~g} / \mathrm{kg}$ ), 运至中国科学院洞庭湖湿地生态系统研 究站进行培养, 确保所有植株处于相同的光照、温度等条件下, 进行除草、浇水等常规管理. 本实验采用双因 素区组设计, 3 个淹水高度 $(-30 、 0$ 和 $30 \mathrm{~cm}$ ), 4 种竞争模式 (全部竞争、无竞争、地上竞争和地下竞争), 4 个 重复. 待新长出的幼苗株高至 $20 \mathrm{~cm}$ 左右时, 进行实验处理. 根据短尖苔草和辣蓼混生群落内的密度确定盆. 
内栽种植物的数量. 2018 年 5 月 11 日, 将长势一 致的 2 株辣苶移栽至高 $30 \mathrm{~cm}$, 直径为 $24 \mathrm{~cm}$ 的塑 料桶内, 其周围移栽 20 株短尖苔草, 作为全部竞争 模式的处理. 根据前人的实践经验, 地上竞争模式 采用长度 $30 \mathrm{~cm}$ 、直径 $15 \mathrm{~cm}$ PVC 管套将辣苶地下 根茎包围, 避免辣苶和短尖苔草地下根茎的竞争; 地下竞争模式采用倒圆台型的塑料网以隔离辣苶 和短尖苔草地上部分的竞争 ${ }^{[40]}$. 无竞争模式 (对照 组) 仅移栽 2 株辣苶. 2018 年 5 月 19 日,将移栽好 植物的塑料桶放人 $2 \mathrm{~m} \times 2 \mathrm{~m} \times 1 \mathrm{~m}$ 的水泥池内, 3 种不同淹水深度下, 4 种竞争模式的塑料桶各有 2 盆,具体如下图所示 (图 2).

本实验共使用 4 个水泥池, 96 盆植物. 将来自 于植物采集地的土壤进行干燥粉碎混匀后用于本 实验. 实验期间, 及时进行水位管理确保水位稳定, 且 7 天更换 1 次自来水. 实验于 2018 年 9 月 19 日 结束, 持续 4 个月.

\section{3 样品采集与分析方法}

实验结束后, 小心将盆内的辣蓼植株从土壤取 出, 用纯净水冲洗干净后, 用吸水纸将植物表面的 水分吸干, 分离 2 株植株的根、茎和叶, 分别称取全 部根、茎和叶的鲜重并记录. 分别将根、茎和叶放人

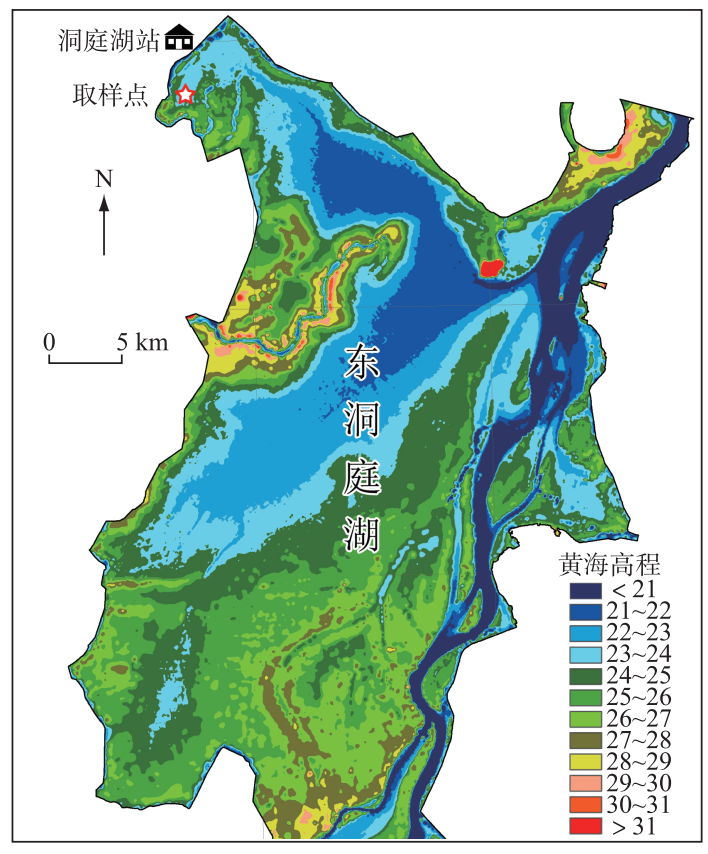

图 1 东洞庭湖取样点位置

Fig. 1 Locations of sampling sites in the East Lake Dongting 烘箱中, $105^{\circ} \mathrm{C}$ 杀青后, 在 $80^{\circ} \mathrm{C}$ 烘干至恒重, 并称取 干重. 分别将烘干后的根、茎和叶进行粉碎, 过 $0.5 \mathrm{~mm}$ 的篮后, 保存备用, 用于测定其碳、氮和磷的含量. 植 物全碳和全氮用 $\mathrm{C} 、 \mathrm{~N}$ 元素分析仪测定; 植物全磷用浓硫酸消煮, 钿锑抗比色法测定. C、N、P 测定结果以单 位质量的养分含量表示 $(\mathrm{mg} / \mathrm{g})$, 生物量则以每盆内植物的干物质量表示 $(\mathrm{g}), \mathrm{C} 、 \mathrm{~N} 、 \mathrm{P}$ 化学计量比均采用摩

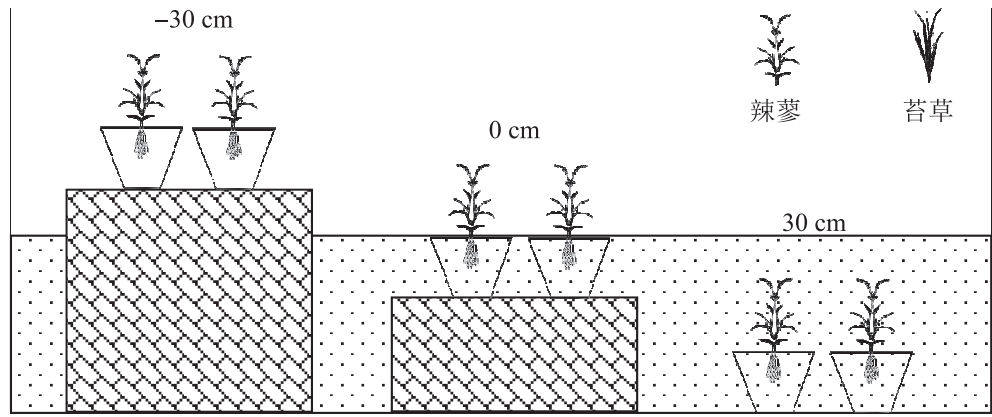

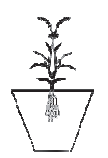

无竞争

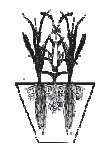

全部竞争

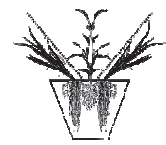

地下竞争

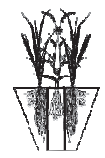

地上竞争

图 2 实验设计示意图

Fig.2 Experimental scheme, showing two plant species ( $P$. hydropiper and C. brevicuspis) growing at three water levels $(-30 \mathrm{~cm}, 0 \mathrm{~cm}, 30 \mathrm{~cm})$, four competition patterns (no competition, full competition, below-ground competition, above-ground competition) conditions 
尔比表示.

\section{4 数据分析与处理}

利用 Excel 2013 和 SAS 8.0 进行数据处理和统计分析,利用 Excel 2013 绘制图表. 数据统计分析前进行 正态分布和方差齐性检验. 利用双因素方差分析 (Two-way ANOVA) 统计各处理间观测指标的差异, 利用 Duncan 检验进行多重比较,显著度水平为 0.05 .

\section{2 结果与分析}

\section{1 生物量}

水位 $(F=56, P<0.0001, d f=2)$ 和竞争模式 $(F=9.94, P<0.0001, d f=3)$ 及两因素的交互作用 $(F=9.76$, $P<0.0001, d f=6)$ 均对辣苶生物量产生显著影响. 由图 3 可知, 水位显著影响不同竞争模式下的辣苶生物量 积累. $-30 \mathrm{~cm}$ 水位下, 无竞争模式的辣苶生物量显著高于其他竞争模式. $30 \mathrm{~cm}$ 水位下, 无竞争模式的辣苶 生物量最低. $-30 \mathrm{~cm}$ 水位下, 不同竞争模式下的辣蓼生物量差异明显, 无竞争模式最高, 地下竞争模式次之, 地上竞争和全部竞争模式最低. 在 $0 \mathrm{~cm}$ 和 $30 \mathrm{~cm}$ 水位下,不同竞争模式下的辣苶生物量无明显差异.

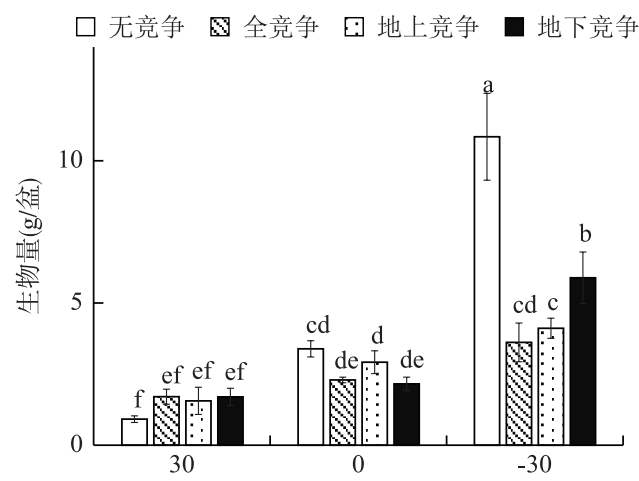

图 3 不同水位和竞争模式下的辣蓼生物量 (数据为平均值土标准误差, 不同字母表示差异显著 $P<0.05$ )

Fig.3 Biomass accumulation of $P$. hydropiper ( means \pm S.E.) under different water-levels and competition patterns (Different letters indicate significant differences among treatment at the 0.05 significance level)

\section{2 叶片的生态化学计量特征}

由图 4 可知, 叶片碳含量在各处理间无显著差异 $(P>0.05)$, 平均值为 $391.5 \pm 5.5 \mathrm{mg} / \mathrm{g}$. 水位处理对辣蓼 叶片的氮、磷含量影响显著 $(P<0.05), 30 \mathrm{~cm}$ 水位下, 氮、磷含量显著高于其他水位下的含量 $(P<0.05)$. 在 $-30 \mathrm{~cm}$ 水位下, 叶片 $\mathrm{C}: \mathrm{N}$ 和 $\mathrm{C}: \mathrm{P}$ 显著高于其他水位下的比值 $(P<0.05) .30 \mathrm{~cm}$ 和 $0 \mathrm{~cm}$ 水位下,无竞争模式 的叶片 $\mathrm{C}: \mathrm{N}$ 和 $\mathrm{C}: \mathrm{P}$ 显著低于有竞争的叶片 $(P<0.05) .0 \mathrm{~cm}$ 水位下, 叶片 $\mathrm{N}: \mathrm{P}$ 显著低于其他水位下的比值 $(P<0.05)$, 为 $10.0 \pm 0.17,30 \mathrm{~cm}$ 和 $-30 \mathrm{~cm}$ 水位下分别为 $11.8 \pm 0.54$ 和 $12.5 \pm 0.47$.

\section{3 茎的生态化学计量特征}

由图 5 可知,水位处理对辣苶茎的碳、氮、磷含量影响显著 $(P<0.05)$. 在 $30 \mathrm{~cm}$ 水位下, 茎碳含量显著低 于其他水位下的含量 $(P<0.05)$; 在 $30 \mathrm{~cm}$ 水位下, 茎氮含量显著高于其他水位下的含量 $(P<0.05) ; 0 \mathrm{~cm}$ 水 位下, 茎磷含量显著高于其他水位下的含量 $(P<0.05)$. 在 $30 \mathrm{~cm}$ 水位下, 茎 $\mathrm{C}: \mathrm{N}$ 显著低于其他水位下的比 值 $(P<0.05) ;-30 \mathrm{~cm}$ 水位下, 茎 $\mathrm{C}: \mathrm{P}$ 显著高于其他水位下的比值 $(P<0.05)$; 茎 $\mathrm{N}: \mathrm{P}$ 大小的顺序为 $30 \mathrm{~cm}$ 水 位 $>-30 \mathrm{~cm}$ 水位 $>0 \mathrm{~cm}$ 水位, 其值分别为 $7.62 \pm 0.59 、 6.23 \pm 0.42$ 和 $4.17 \pm 0.12 .-30 \mathrm{~cm}$ 水位和无竞争模式下的 茎 $\mathrm{P}$ 含量最低, 同时 $\mathrm{C}: \mathrm{P}$ 和 $\mathrm{N}: \mathrm{P}$ 最大.

\section{4 根的生态化学计量特征}

由图 6 可知,水位处理对辣苶根的碳、氮、磷含量影响显著 $(P<0.05)$. 在 $30 \mathrm{~cm}$ 水位下,根碳含量显著低 于其他水位下的含量 $(P<0.05)$; 在 $30 \mathrm{~cm}$ 水位下, 根氮含量显著最高 $(P<0.05)$, 其次为 $0 \mathrm{~cm}$ 水位, $-30 \mathrm{~cm}$ 

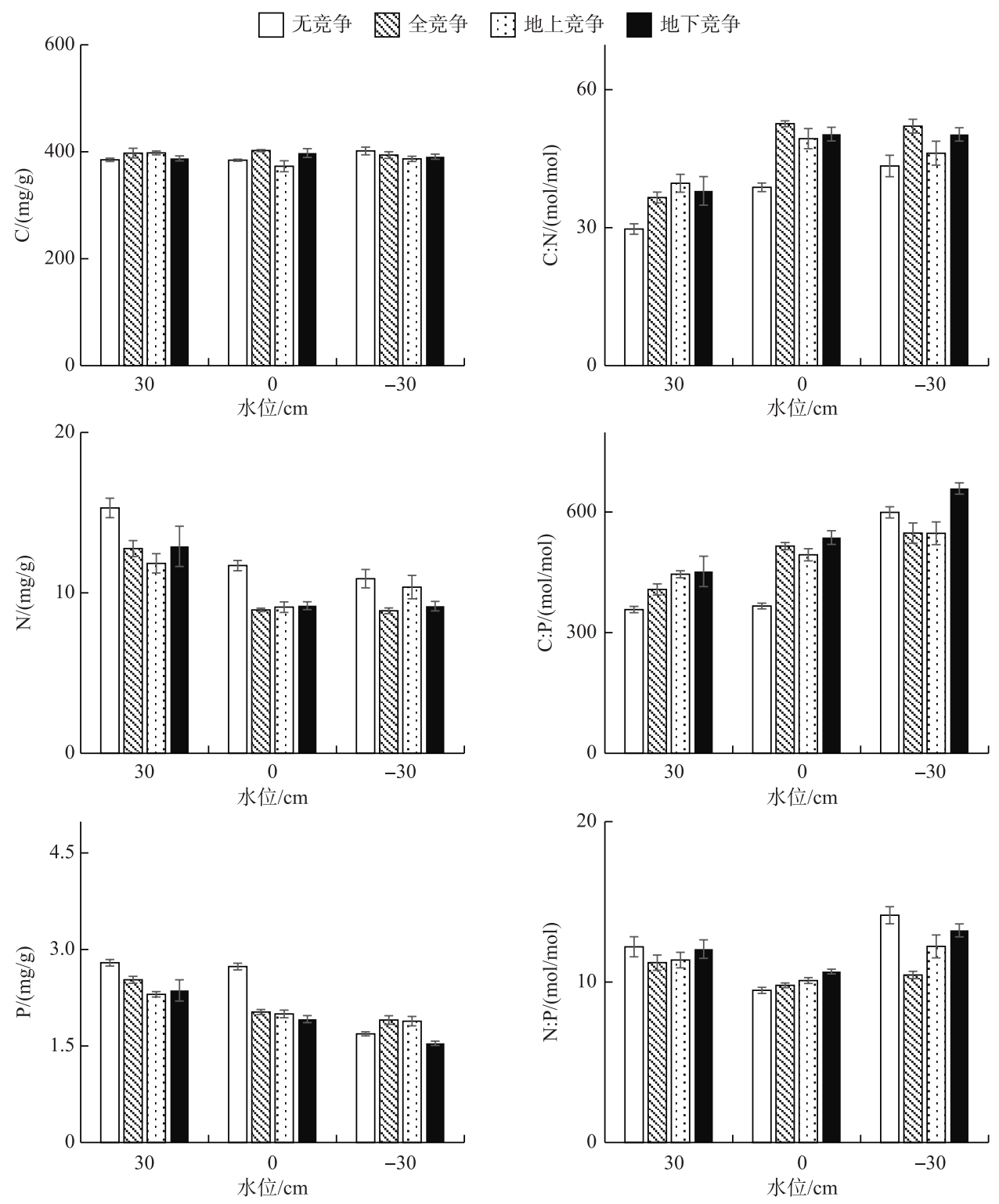

图 4 辣蓼叶的 C、N、P 含量及其化学计量比

Fig.4 C, N and P contents and their ratios of P. hydropiper leaf

水位; $0 \mathrm{~cm}$ 水位下, 根磷含量显著高于 $-30 \mathrm{~cm}$ 水位下的含量 $(P<0.05)$. 在 $30 \mathrm{~cm}$ 水位下, 根 $\mathrm{C}: \mathrm{N}$ 显著低于其 他水位下的比值 $(P<0.05),-30 \mathrm{~cm}$ 水位下根 $\mathrm{C}: \mathrm{N}$ 最高, 其次为 $0 \mathrm{~cm}$ 水位; $-30 \mathrm{~cm}$ 水位下, 根 $\mathrm{C}: \mathrm{P}$ 显著高于 其他水位下的比值 $(P<0.05) ; 30 \mathrm{~cm}$ 水位下, 根 $\mathrm{N}: \mathrm{P}$ 显著高于其他水位下的含量 $(P<0.05)$, 其值为 $8.81 \pm$ $0.47 .30 \mathrm{~cm}$ 水位和无竞争模式下的根 $\mathrm{N}$ 含量最高, 同时 $\mathrm{N}: \mathrm{P}$ 最大.

\section{3 讨论}

\section{1 水位和竞争作用对辣苶生物量的影响}

湿地植物的生长繁殖、群落分布等主要受水文过程的制约. 通常不同水位高程的植被受到的淹水强度 

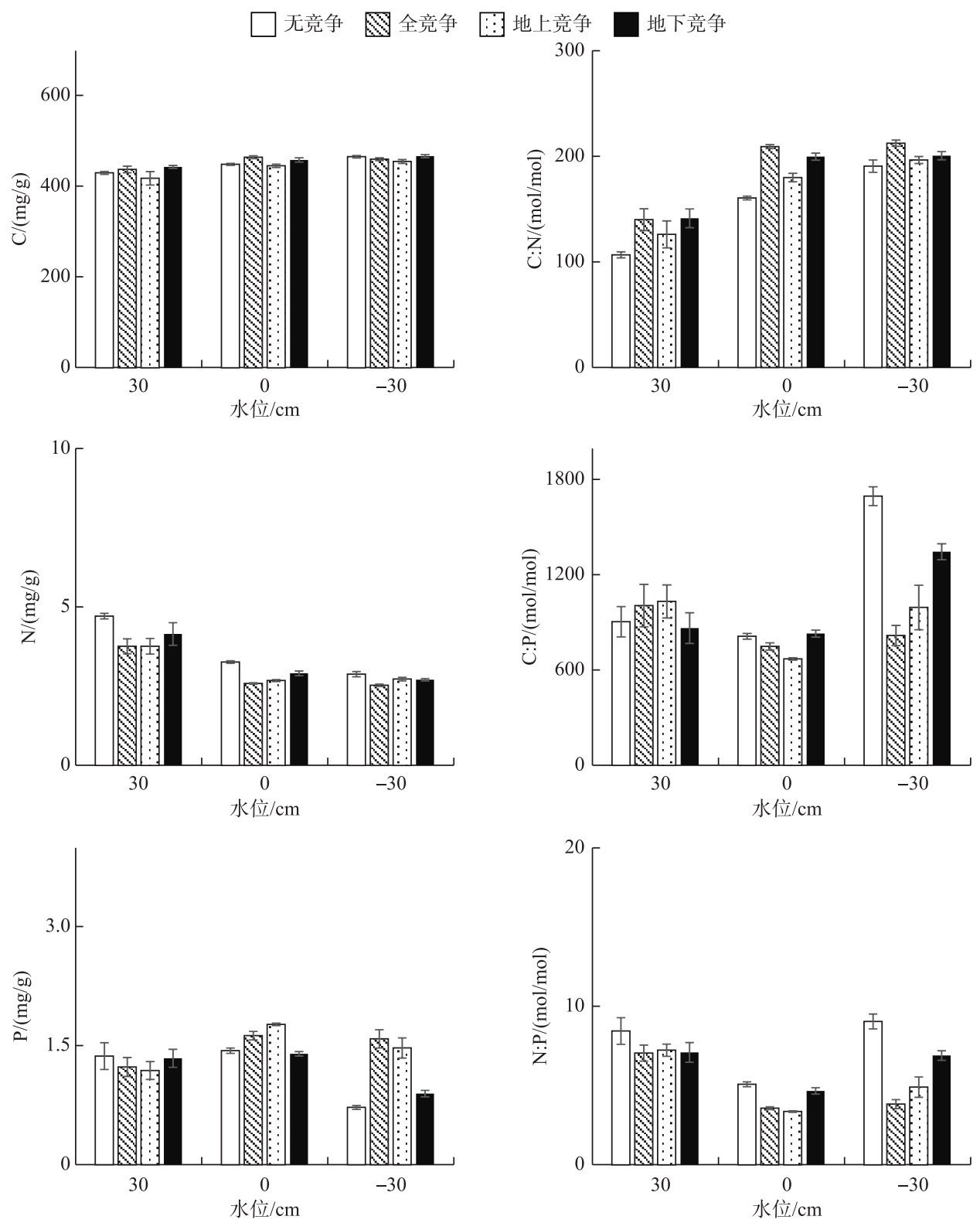

图 5 辣苶茎的 $\mathrm{C} 、 \mathrm{~N} 、 \mathrm{P}$ 含量及其生态化学计量比

Fig.5 C, N and P contents and their ratios of $P$. hydropiper stem

有明显差异,植物适应性的变化也不同. 有研究表明,湿地植物生物量的变化是对外界环境变化的综合响 应, 植物为了获得更多的资源、度过胁迫环境而调节自身最优的生物量分配 ${ }^{[41]}$. 淹没条件抑制植物生物量 的增加, 可能是因为土壤缺氧抑制植物根系呼吸作用, 进而减少根系对土壤养分的吸收 ${ }^{[42-43]}$, 造成植物体内 可溶性糖、淀粉等营养含量减小 ${ }^{[44]}$. 水位增加抑制植物叶片呼吸作用和光合作用, 导致株高和密度增长缓 慢、叶片调落. 在本实验中辣苶总生物量随水位增加显著下降, 这与 Chen 的结果相一致 ${ }^{[45]}$. 竞争作用通过 调节植物对营养和光照的吸收, 从而影响植物的生物量积累. 然而, $30 \mathrm{~cm}$ 水位下, 无竞争组的生物量比有竞 争组的生物量小, 其可能的原因是植物间的竞争作用已经转化为促进作用. 这种促进作用的机制可能是由 

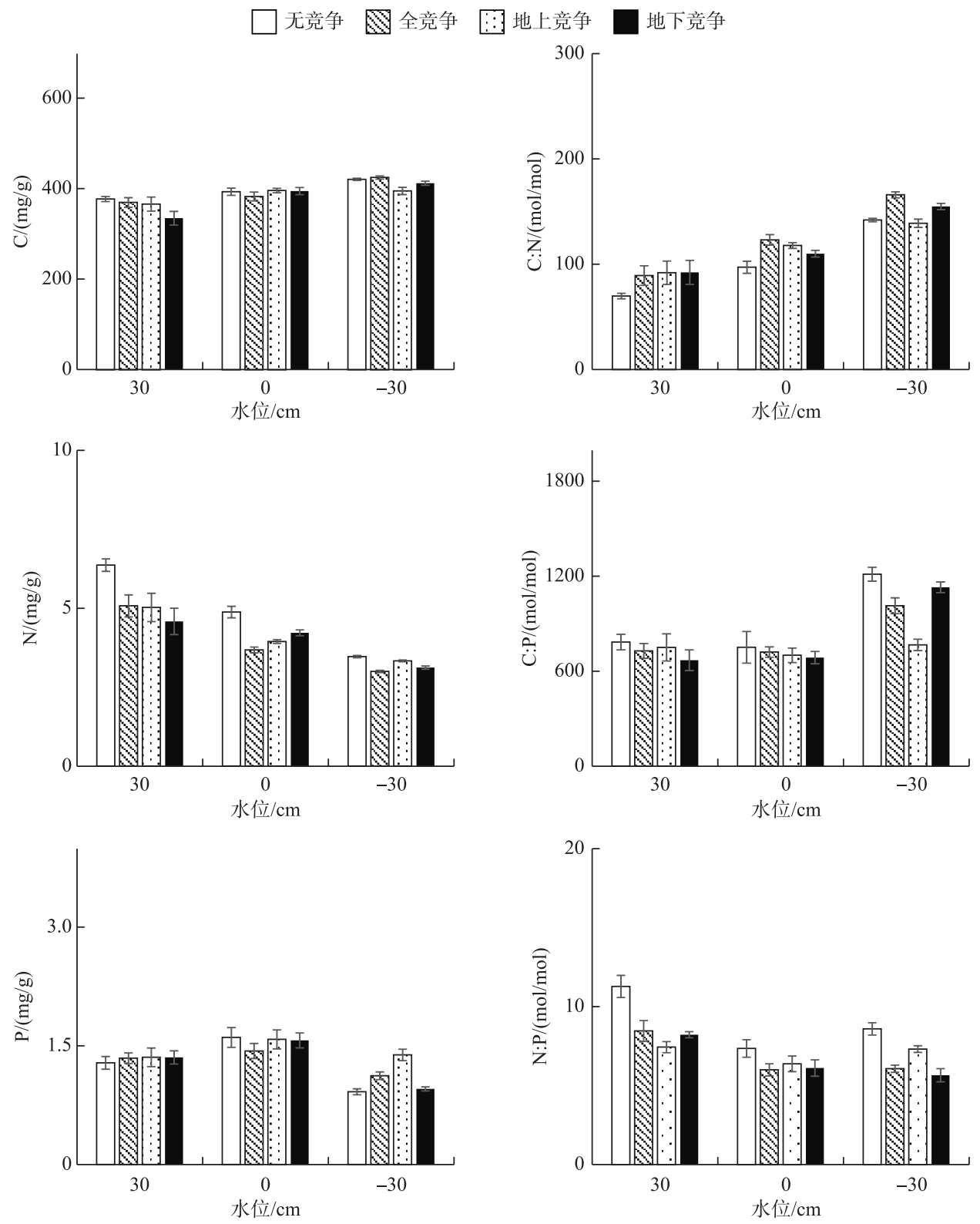

图 6 辣蓼根的 $\mathrm{C} 、 \mathrm{~N} 、 \mathrm{P}$ 含量及其生态化学计量比

Fig.6 C, N and P contents and their ratios of P. hydropiper root

于具发达的叶通气组织的苔草与其发达的根系统共同组成了高效的气体管道系统, 可以向土壤中释放氧 气, 在高水位时可以减轻土壤缺氧状况 ${ }^{[46]}$. 在 $30 \mathrm{~cm}$ 和 $0 \mathrm{~cm}$ 水位梯度下, 不同竞争模式下的生物量间无显 著差异, 说明外界环境胁迫的作用较植物的特定特征更能影响植物与植物的相互作用关系 ${ }^{[47]}$. 因此, 洞庭 湖水位变化比植物的竞争作用更能影响植物的生长和分布.

\section{2 水位对辣蓼生态化学计量特征的影响}

在湿地生态系统中, 耐淹性植物可以通过改变代谢途径或者适应性机制以保证淹水环境下的生存和生 长, 这些调节对植物的养分吸收具有显著影响, 进而影响植物生态化学计量特征. 根据生长速率假说, 生长 
速率较高的植物体具有较低的 $\mathrm{C}: \mathrm{P}$ 和 $\mathrm{N}: \mathrm{P}$ 值, 原因是虽然不同物种间的元素含量和比值不同, 但是随着生 长速率的增加, 植物体的氮和磷含量都会增加, 其中磷含量增加的速度大于氮含量增加的速度 ${ }^{[48-50]}$, 这与分 配到 rRNA 中的磷元素增加有关 ${ }^{[51]}$. 本实验中, 在淹没条件下辣苶叶片总氮和总磷含量均高于其他条件下 的总氮、总磷含量. 该研究结果与 Cronin and Lodge 的相似, 其认为较强的光照能导致叶片氮含量较低, 这可 能是因为叶片固碳作用的增强, 稀释了有效氮的含量 ${ }^{[52]}$. 另外的原因可能是长时间的淹水促使植物通过增 强叶片的生理代谢能力来适应淹水环境 ${ }^{[53]}$. 植物体 $\mathrm{C}: \mathrm{N}$ 和 $\mathrm{C}: \mathrm{P}$ 值被用来表示养分利用效率, 即植物吸收营 养元素时同化碳的能力 ${ }^{[54-55]}$. 本研究结果表明, $-30 \mathrm{~cm}$ 水位处理辣苶叶片、茎和根的 $\mathrm{C}: \mathrm{N}$ 和 $\mathrm{C}: \mathrm{P}$ 值大于其 他处理的比值, 说明该条件下辣苶对养分的利用效率较高. 综上所述, $30 \mathrm{~cm}$ 水位条件下辣苶通过向叶片中 组织氮磷的输人, 维持正常的生理功能, 获取较高的生长速率, 减缓水分的胁迫作用, 表明其可能采用竞争 性生长策略; $-30 \mathrm{~cm}$ 水位条件下辣苶茎和根含碳量较高, 表明辣蓼通过增加对茎和根碳的分配, 提高防御能 力来适应不利的生长环境 ${ }^{[56]}$.

\section{3 竞争作用对辣苶生态化学计量特征的影响}

竞争的主要形式表现为发生在相邻植物之间对地上 (光、热) 和地下资源 (水分、矿质营养) 的争夺, 体 现了个体获得资源的能力并籍此限制其它个体获得资源的能力. 本实验中, $-30 \mathrm{~cm}$ 水位竞争情况下, 地下竞 争模式下的辣蓼生物量积累较全竞争模式和地上竞争模式下显著增多, 说明非胁迫条件下,辣苶和苔草间 的竞争主要体现为地上部分对于光的竞争, 这与 Keddy 的研究结果相一致 ${ }^{[57]}$. 但是在其他水位条件下, 植 物间地上竞争、地下竞争和全竞争对生物量积累的影响有限, 其原因可能是相比植物间的相互作用,外界环 境胁迫作用更能影响植物的生长作用和植物间的相互作用 ${ }^{[47]}$. 本实验表明相比于无竞争组, 竞争作用下的 辣苶叶、茎和根的总氮含量降低, 而 $\mathrm{C}: \mathrm{N}$ 值增加, $\mathrm{N}: \mathrm{P}$ 值降低, 这与 Broadbent 等的研究结果相一致 ${ }^{[58]}$. 这可 能因为竞争作用导致辣苶对氮的吸收减少, 从而 $\mathrm{C}: \mathrm{N}$ 值增加, $\mathrm{N}: \mathrm{P}$ 值降低. 另有研究表明种间竞争对植物组 织内营养元素比例的改变和这种变化的大小取决于物种特性和营养元素本身 ${ }^{[30]}$. 如: 竞争过程中有些物种 会提高营养元素的利用效率, 而有些物种则倾向于吸收和积累更多的营养元素. 辣苶和短尖苔草的竞争过 程对生态化学计量特征的影响机制还需要进一步的研究.

\section{4 结论}

1) 水位处理显著影响不同竞争模式下的生物量积累, 辣苶生物量随水位增加显著降低; 在 $30 \mathrm{~cm}$ 和 0 $\mathrm{cm}$ 水位梯度下, 不同竞争模式下的生物量间无显著差异, 说明外界环境胁迫的作用较植物的特定特征更能 影响植物与植物的相互作用关系. $30 \mathrm{~cm}$ 水位下, 无竞争组的生物量比有竞争组的生物量小, 其可能的原因 是植物间的竞争作用已经转化为促进作用.

2) 水位处理对辣苶叶片、茎和根的氮、磷含量影响显著. $30 \mathrm{~cm}$ 水位下, 辣苶叶片氮磷含量显著高于其他 水位下的含量, 辣蓼通过向叶片中组织氮、磷的输人, 维持正常的生理功能, 获取较高的生长速率, 减缓水分 的胁迫作用, 表明其可能采用竞争性生长策略; 在 $-30 \mathrm{~cm}$ 水位下, 叶片 $\mathrm{C}: \mathrm{N}$ 和 $\mathrm{C}: \mathrm{P}$ 显著高于其他水位下的 比值, 且辣蓼茎和根含碳量较高, 表明辣苶通过增加对茎和根碳的分配, 提高防御能力来适应不利的生长 环境.

3) 相比于无竞争组, 竞争作用下的辣苶总氮含量降低, 而 $C: N$ 值增加, $N: P$ 值降低. 这可能因为竞争作 用导致辣苶对氮的吸收减少所致, 而种间竞争对植物组织内营养元素比例的改变大小取决于物种特性和营 养元素本身.

\section{5 参考文献}

[ 1 ] Zeng DH, Chen GS. Ecological stoichiometry: A science to explore the complexity of living systems. Chinese Journal of Plant Ecology, 2005, 29(6) : 1007-1019. [曾德慧, 陈广生. 生态化学计量学:复杂生命系统奥秘的探索. 植物生态 学报, 2010, 29(6): 1007-1019.]

[ 2 ] Elser JJ, Sterner RW, Gorokhova E et al. Biological stoichiometry from genes to ecosystems. Ecology Letters, 2000, 3: 540-550.

[ 3 ] Wang SQ, Yu GR. Ecological stoichiometry characteristics of ecosystem carbon, nitrogen and phosphorus elements. Acta 
Ecologica Sinica, 2008, 28(8) : 3937-3947. [王绍强, 于贵瑞. 生态系统碳氮磷元素的生态化学计量学特征. 生态 学报, 2008, 28(8): 3937-3947.]

[ 4 ] Bradshaw C, Kautsky U, Kumblad L. Ecological stoichiometry and multi-element transfer in a coastal ecosystem. Ecosystems, 2012, 15: 591-603.

[ 5 ] Luo WP, Xie YH, Song FB. Survival strategies of wetland plants in flooding environments. Chinese Journal of Ecology, 2007, 26 (9) : 1478-1485. [罗文泊, 谢永宏, 宋凤斌. 洪水条件下湿地植物的生存策略. 生态学杂志, 2007,26 (9) : 1478-1485.]

[ 6 ] Yang J, Li EH, Cai XB et al. Research progress in response of plants in wetlands to water level change. Wetland Science, 2014, 12(6) : 807-813. [杨娇, 厉恩华, 蔡晓斌等. 湿地植物对水位变化的响应研究进展. 湿地科学, 2014,12 (6) : 807-813.]

[ 7 ] Voesenek L, Rijnders J, Peeters AJ et al. Plant hormones regulate fast shoot elongation under water: From genes to communities. Ecology, 2004, 85: 16-27.

[ 8 ] Lowe BJ, Watts RJ, Roberts J et al. The effect of experimental inundation and sediment deposition on the survival and growth of two herbaceous riverbank plant species. Plant Ecology, 2010, 209: 57-69.

[ 9 ] Saaltink RM, Dekker SC, Griffioen J et al. Vegetation growth and sediment dynamics in a created freshwater wetland. Ecological Engineering, 2018, 111: 11-21.

[10] Sardans J, Rivas-Ubach A, Peñuelas J. The elemental stoichiometry of aquatic and terrestrial ecosystems and its relationships with organismic lifestyle and ecosystem structure and function: A review and perspectives. Biogeochemistry, 2012, 111: $1-39$.

[11] Guillaume R, Margret S. Ethylene biosynthesis and signaling in rice. Plant Science, 2008, 175: 32-42.

[12] Visser EJ, Bögemann GM, Steeg HM et al. Flooding tolerance of Carex species in relation to field distribution and aerenchyma formation. New Phytologist, 2010, 148: 93-103.

[13] Luo WP, Xie YH. Growth and morphological responses to water level and nutrient supply in three emergent macrophyte species. Hydrobiologia, 2009, 624: 151-160.

[14] Mommer L, Visser EJ. Underwater photosynthesis in flooded terrestrial plants: A matter of leaf plasticity. Annals of Bota$n y, 2005,96: 581-589$.

[15] Chen XS, Li YF, Cai YH et al. Differential strategies to tolerate flooding in polygonum hydropiper plants originating from low- and high-elevation habitats. Frontiers in Plant Science, 2019, 9: 1-9.

[16] Gibbs J, Greenway H. Mechanisms of anoxia tolerance in plants. I. Growth, survival and anaerobic catabolism. Functional Plant Biology, 2003, 30: 1-47.

[17] Panda D, Sharma SG, Sarkar RK. Chlorophyll fluorescence parameters, $\mathrm{CO}_{2}$ photosynthetic rate and regeneration capacity as a result of complete submergence and subsequent re-emergence in rice (Oryza sativa L.). Aquatic Botany, 2008, 88: 127-133.

[18] He Y, Zhang YH, Yu JY et al. Effect of waterlogging on the contents of C, N and tannins of Kandelia candel seedlings: a test of the carbon-nutrient balance hypothesis. Acta Ecologica Sinica, 2008, 28(10): 4725-4731. [何缘, 张宜辉, 于俊 义等. 淹水胁迫对秋茄幼苗叶片 $\mathrm{C} 、 \mathrm{~N}$ 及单宁含量的影响一一个关于碳素-营养平衡假说的实验. 生态学报, $2008,28(10): 4725-4731$. ]

[19] Xiao Q, Zheng HL, Chen Y et al. Effects of salinity on the growth and proline, soluble sugar and protein contents of Spartina alterniflora. Chinese Journal of Ecology, 2005, 24(4) : 373-376. [肖强, 郑海雷, 陈瑶等. 盐度对互花米草生长 及脯氨酸、可溶性糖和蛋白质含量的影响. 生态学杂志, 2005, 24(4) : 373-376. ]

[20] Wang T, Wei H, Ma W et al. Response of Taxodium distichum to winter submergence in the water-level-fluctuating zone of the Three Gorges Reservoir region. Journal of Freshwater Ecology, 2019, 34: 1-17.

[21] Hacker SD, Gaines SD. Some implications of direct positive interactions for community species diversity. Ecology, 1997, 78: 1990-2003.

[22] Brooker RW, Maestre FT, Callaway RM et al. Facilitation in plant communities: the past, the present, and the future. Journal of Ecology, 2008, 96: 18-34.

[23] Le Bagousse-Pinguet Y, Xiao S, Brooker RW et al. Facilitation displaces hotspots of diversity and allows communities to persist in heavily stressed and disturbed environments. Journal of Vegetation Science, 2014, 25: 66-76. 
[24] Li F, Yang N, Zhu LL et al. Competition and facilitation of two wetland macrophytes under different water levels and nutrient-heterogeneous conditions. Freshwater Science, 2018, 37: 296-306.

[25] McPhee CS, Aarssen LW. The separation of above- and below-ground competition in plants a review and critique of methodology. Plant Ecology, 2001, 152(2) : 119-136.

[26] James F, Cahill J. Fertilization effects on interactions between above- and belowground competition in an old field. Ecolo$g y, 1999, \mathbf{8 0}(2): 466-480$.

[27] Wilson SD, Tilman D. Competitive responses of eight old-field plant species in four environments. Ecology, 1995, 76(4): 1169-1180.

[28] Francisco IP, Maria TL. Changes in plant interactions along a gradient of environmental stress. Oikos, 2001, 93(1): $42-49$.

[29] Lamb EG, Kembel SW, Cahill JF. Shoot, but not root, competition reduces community diversity in experimental mesocosms. Journal of Ecology, 2009, 97: 155-163.

[30] Matos CC, Costa MD, Silva IR et al. Competitive capacity and rhizosphere mineralization of organic matter during weedsoil microbiota interactions. Planta Daninha, 2019, 37.

[31] Christiano CM, Rafael ST, Ivo Ribeiro da S et al. Interspecific competition changes nutrient : nutrient ratios of weeds and maize. Journal of Plant Nutrition and Soil Science, 2019, 182: 286-295.

[32] Li X, Li F, Xie YH et al. Vegetation dynamics of Triarrhena sacchariflora and Carex sp. community ecotone and determining factors in Lake Dongting: A case study in the Beizhouzi lake-shore. J Lake Sci, 2015, 27(6) : 1020-1026. DOI: 10. $18307 / 2015.0605$. [李旭, 李峰, 谢永宏等. 洞庭湖荻-苔草群落交错带植被动态及影响因子一一以北洲子洲滩为 例. 湖泊科学, $2015,27(6): 1020-1026$. ]

[33] Li F, Qin XY, Xie YH et al. Physiological mechanisms for plant distribution pattern: responses to flooding and drought in three wetland plants from Lake Dongting, China. Limnology, 2012, 14: 71-76.

[34] Li F, Xie YH, Yang GS et al. Interactive influence of water level, sediment heterogeneity, and plant density on the growth performance and root characteristics of Carex brevicuspis. Limnologica, 2017, 62: 111-117.

[35] Chen J, Miao FJ, Yang WZ et al. A preliminary study on impacts of the elevation on plants' distribution patterns in seasonal wetland of Lake Napahai. J Lake Sci, 2015, 27(3) : 392-400. DOI: 10.18307/2015.0304. [陈剑, 缪福俊, 杨文忠 等. 海拔对纳帕海季节性湿地植被分布格局影响初探. 湖泊科学, 2015, 27(3): 392-400.]

[36] He L, Chen XX Li W et al. Leaf carbon, nitrogen and phosphorus stoichiometric characteristics and photosynthetic pigments composition of four submerged macrophytes in response to various water depth in Lake Erhai. J Lake Sci, 2018, 30 (5) : 1413-1419. DOI: 10.18307/2018.0522. [何亮, 陈晓希, 李威等. 洱海 4 种沉水植物叶片的光合色素组成及 C、N、P 化学计量特征对水深的响应. 湖泊科学, 2018, 30(5) : 1413-1419.]

[37] Cao T, Ni L, Xie P et al. Effects of moderate ammonium enrichment on three submersed macrophytes under contrasting light availability. Freshwater Biology, 2011, 56: 1620-1629.

[38] Miao SL, Zou CB. Effects of inundation on growth and nutrient allocation of six major macrophytes in the Florida Everglades. Ecological Engineering, 2012, 42: 10-18.

[39] Yuan GX, Cao T, Fu H et al. Linking carbon and nitrogen metabolism to depth distribution of submersed macrophytes using high ammonium dosing tests and a lake survey. Freshwater Biology, 2013, 58: 2532-2540.

[40] Mcphee CS, Aarssen LW. The separation of above- and below-ground competition in plants : A review and critique of methodology. Plant Ecology, 2001, 152: 119-136.

[41] Wright SD, Mcconnaughay KD. Interpreting phenotypic plasticity: the importance of ontogeny. Plant Species Biology, 2010, 17: 119-131.

[42] Su HJ, Wu Y, Xie P et al. Effects of taxonomy, sediment, and water column on C: N:P stoichiometry of submerged macrophytes in Yangtze floodplain shallow lakes, China. Environmental Science and Pollution Research, 2016, 23: 22577-22585.

[43] Voesenek LA, Colmer TD, Pierik R et al. How plants cope with complete submergence. New Phytologist, 2010, 170: 213-226.

[44] Jackson MB, Ram PC. Physiological and molecular basis of susceptibility and tolerance of rice plants to complete submergence. Annals of Botany, 2003, 91 : 227-241. 
[45] Chen XS, Li YF, Cai YH et al. Differential strategies to tolerate flooding in Polygonum hydropiper plants originating from lowand high-elevation habitats. Frontiers in Plant Science, 2019, 9:1970.

[46] Qin XY, Xie YH, Chen XS. Competition and facilitation among wetland plants: A review. Chinese Journal of Ecology, 2010, 29 (1) : 117-123. [秦先燕, 谢永宏, 陈心胜. 湿地植物间竞争和促进互作的研究进展. 生态学杂志, 2010, 29(1): 117-123.]

[47] He Q, Bertness MD, Altieri AH. Global shifts towards positive species interactions with increasing environmental stress. Ecology Letter, 2013, 16: 695-706.

[48] Elser JJ, O'Brien WJ, Dobberfuhl DR et al. The evolution of ecosystem processes: growth rate and elemental stoichiometry of a key herbivore in temperate and arctic habitats. Journal of Evolutionary Biology, 2000, 13 : 845-853.

[49] Karl DM, Björkman KM, Dore JE et al. Ecological nitrogen-to-phosphorus stoichiometry at station ALOHA. Deep-Sea Research Part II, 2001, 48: 1529-1566.

[50] Güsewell S. N: P ratios in terrestrial plants: variation and functional significance. New Phytologist, 2004, 164: 243-266.

[51] Acharya K, Kyle M, Elser JJ. Biological stoichiometry of Daphnia growth: An ecophysiological test of the growth rate hypothesis. Limnology and Oceanography, 2004, 49: 656-665.

[52] Cronin G, Lodge DM. Effects of light and nutrient availability on the growth, allocation, carbon/nitrogen balance, phenolic chemistry, and resistance to herbivory of two freshwater macrophytes.Oecologia, 2003, 137: 32-41.

[53] Li YC, Chen SL, Yue YD et al. Effect of continuous flooding stress on nutrient element distribution patterns in Phyllostachys rivalis modules. Acta Ecologica Sinica, 2017, 37(10): 3482-3493. [李迎春, 陈双林, 岳永德等. 持续淹水对 河竹器官养分元素分配格局的影响. 生态学报, 2017, 37(10): 3482-3493. ]

[54] Herbert DA, Williams M, Rastetter EB. A model analysis of N and P limitation on carbon accumulation in Amazonian secondary forest after alternate land-use abandonment. Biogeochemistry, 2003, 65: 121-150.

[55] You C, Mo X, Zhang S et al. The stoichiometric characteristics of different plant communities in the Duliujian River estuary. Chinese Journal of Applied and Environment Biology, 2019, 25(3) : 617-625. [游冲, 莫雪, 张森等. 天津独流减 河河口不同植物群落的生态化学计量学特征. 应用与环境生物学报, 2019, 25(3): 617-625.]

[56] Huang D, Wang DM, Ren Y. Using leaf nutrient stoichiometry as an indicator of flood tolerance and eutrophication in the riparian zone of the Lijang River. Ecological Indicators, 2019, 98: 821-829.

[57] Keddy TS. Above- and belowground competition intensity in two contrasting wetland plant communities. Ecology, 1996,77 (1) : 259-270.

[58] Broadbent A, Stevens CJ, Peltzer DA et al. Belowground competition drives invasive plant impact on native species regardless of nitrogen availability. Oecologia, 2018, 186: 577-587. 